\title{
Timing and Impact of Psychiatric, Cognitive, and Motor Abnormalities in Huntington Disease
}

Branduff McAllister, BSc, PhD, James F. Gusella, PhD, G. Bernhard Landwehrmeyer, MD, PhD, Jong-Min Lee, PhD, Marcy E. MacDonald, PhD, Michael Orth, MD, PhD, Anne E. Rosser, MB BChir, FRCP, PhD, Nigel M. Williams, BSc, PhD, Peter Holmans, BA, PhD, Lesley Jones, BSc, PhD,* and

Thomas H. Massey, MA, BM BCh, DPhil,* on behalf of the REGISTRY Investigators of the European Huntington's Disease Network

Neurology ${ }^{\circledR}$ 2021;96:e2395-e2406. doi:10.1212/WNL.0000000000011893

\section{Abstract}

\section{Objective}

To assess the prevalence, timing, and functional impact of psychiatric, cognitive, and motor abnormalities in Huntington disease (HD) gene carriers, we analyzed retrospective clinical data from individuals with manifest HD.

\section{Methods}

Clinical features of patients with HD were analyzed for 6,316 individuals in an observational study of the European Huntington's Disease Network (REGISTRY) from 161 sites across 17 countries. Data came from clinical history and the patient-completed Clinical Characteristics Questionnaire that assessed 8 symptoms: motor, cognitive, apathy, depression, perseverative/obsessive behavior, irritability, violent/aggressive behavior, and psychosis. Multiple logistic regression was used to analyze relationships between symptoms and functional outcomes.

\section{Results}

The initial manifestation of $\mathrm{HD}$ is increasingly likely to be motor and less likely to be psychiatric as age at presentation increases and is independent of pathogenic CAG repeat length. The Clinical Characteristics Questionnaire captures data on nonmotor symptom prevalence that correlate specifically with validated clinical measures. Psychiatric and cognitive symptoms are common in HD gene carriers, with earlier onsets associated with longer CAG repeats. Of patients with $\mathrm{HD}, 42.4 \%$ reported at least 1 psychiatric or cognitive symptom before motor symptoms, with depression most common. Each nonmotor symptom was associated with significantly reduced total functional capacity scores.

\section{Conclusions}

Psychiatric and cognitive symptoms are common and functionally debilitating in HD gene carriers. They require recognition and targeting with clinical outcome measures and treatments. However, because it is impossible to distinguish confidently between nonmotor symptoms arising from $\mathrm{HD}$ and primary psychiatric disorders, particularly in younger premanifest patients, nonmotor symptoms should not be used to make a clinical diagnosis of HD.

\author{
Correspondence \\ Dr. Massey \\ masseyt1@cardiff.ac.uk
}

\section{RELATED ARTICLE}

\section{Editorial}

Prevalent Nonmotor

Symptoms Associated With

Huntington Disease:

Challenging to Interpret

and With Early Impact on Function

Page 875

\section{MORE ONLINE}

- CME Course

NPub.org/cmelist

\section{Trial Registration Information}

ClinicalTrials.gov Identifier: NCT01590589

\footnotetext{
*These authors contributed equally to this work as senior authors.

From the Division of Psychological Medicine and Clinical Neurosciences (B.M., N.M.W., P.H., L.J., T.H.M.), Brain Repair Group (A.E.R.), Schools of Medicine and Biosciences, and Neuroscience and Mental Health Research Institute (A.E.R.), Cardiff University, UK; Molecular Neurogenetic Unit (J.F.G., J.-M.L., M.E.M.), Center for Genomic Medicine, Massachusetts General Hospital; Department of Genetics (J.F.G., J.-M.L., M.E.M.), Harvard Medical School, Boston, MA; Department of Neurology (G.B.L.), University of Ulm, Germany; and Swiss Huntington's Disease Centre (M.O.), Siloah, Bern, Switzerland.

Go to Neurology.org/N for full disclosures. Funding information and disclosures deemed relevant by the authors, if any, are provided at the end of the article.

The Article Processing Charge was funded by Medical Research Council (UK).

Coinvestigators are listed in the appendix 2 at links.Iww.com/WNL/B358.
}

This is an open access article distributed under the terms of the Creative Commons Attribution License 4.0 (CC BY), which permits unrestricted use, distribution, and reproduction in any medium, provided the original work is properly cited. 


\section{Glossary}

CI = confidence interval; EHDN = European Huntington's Disease Network; HADS = Hospital Anxiety/Depression Scale; HD = Huntington disease; HDCCQ $=$ HD Clinical Characteristics Questionnaire; ICD-10 = International Classification of Disease, 10 th revision; OR = odds ratio; PBA-s = short form of the Problem Behaviours Assessment; PREDICT-HD = Neurobiological Predictors of Huntington's Disease; REGISTRY = An Observational Study of the European Huntington's Disease Network; SDMT = Symbol-Digit Modalities Test; SIS = Snaith Irritability Scale; TFC = total functional capacity; TMS = total motor score; UHDRS = Unified Huntington's Disease Rating Scale.

Huntington disease (HD) is a central neurodegenerative disorder caused by an expanded CAG repeat (>35 CAGs) in the Huntingtin gene. ${ }^{1}$ Longer repeats are associated with earlier disease onset. ${ }^{2,3}$ Neuronal loss in the brain causes progressive motor abnormalities, cognitive decline, and ultimately death. The movement disorder usually includes chorea but may also involve dystonia, ataxia, oculomotor problems, and parkinsonism, some of which are initially identifiable only through targeted HD examination. Debilitating behavioral and psychiatric symptoms are common in HD gene carriers and require treatment, although they cannot be used in clinical practice to define $\mathrm{HD}$ onset because it is impossible to distinguish psychiatric manifestations of $\mathrm{HD}$ from coincident diagnoses. ${ }^{4,5}$ Prospective studies of HD gene carriers many years from predicted clinical onset have shown only subtle motor, cognitive, and psychiatric deficits compared with ageand sex-matched controls. ${ }^{6-8}$ This implies that there is a window for therapeutic intervention to preserve normal brain functions. Understanding in detail the timing and impact of different symptoms in HD gene carriers will help improve targeted therapies.

The HD Clinical Characteristics Questionnaire (HD-CCQ $)^{9}$ gathers retrospective data from individuals with $\mathrm{HD}$ about the prevalence and timing of 8 motor, cognitive, and psychiatric symptoms. ${ }^{10}$ Here, we validate HD-CCQ data for nonmotor symptoms by showing strong and specific associations with established scores of depression, irritability, and cognition. We use HD-CCQ data to show the high prevalence of psychiatric and cognitive symptoms in HD gene carriers, often in advance of motor symptoms, and their negative impact on the lives of patients.

\section{Methods}

\section{Standard Protocol Approvals, Registrations, and Patient Consents}

Participants were in the multicenter, multinational An Observational Study of the European Huntington's Disease Network (REGISTRY) study of European HD (ehdn.org/wp-content/ uploads/2018/06/registry-protocol-3.0.pdf; NCT01590589). Data were accessed as part of European Huntington's Disease Network (EHDN) data mining project 0791. Ethics approval for REGISTRY was obtained in each participating country. All participants gave written informed consent.

\section{Participant Data}

HD participant data, collected from June 2004 to February 2016 across 161 sites in 17 European countries, were obtained for 6,316 individuals (accessed October 2016) who had clinical HD onset, determined by the rating clinician in REGISTRY, and a confirmed pathogenic CAG length of 36 to 93 . Of these CAG sizes, 5,027 were centrally determined by BioRep Inc (Milan, Italy; REGISTRY protocols), and 1,289 were derived by local diagnostic laboratories. Two estimates of the age at onset of symptoms or signs in HD were used in this study. First, the clinician-estimated age at first HD manifestation was based on all available clinical evidence at the first REGISTRY visit (coded as sxrater). Having an sxrater age at onset was required for inclusion in this study. Onset type was classified as motor, cognitive, psychiatric, oculomotor, other, or mixed. Because the clinician's estimate was given as a date, age estimates were calculated from the participant's anonymized birthday; when only a year was given, July 15 was used for estimation (15/07/ $\mathrm{xxxx})$. Second, the ages at onset of different symptoms in patients with $\mathrm{HD}$ were estimated by the $\mathrm{HD}-\mathrm{CCQ}$, which was completed by a health care professional, usually an HD-specialist nurse or similarly qualified person, using responses from the individual with $\mathrm{HD}$ and their care partners (present in clinic in $93.1 \%$ of cases) and patient medical notes. The HD-CCQ comprises questions about 8 symptoms commonly observed in $\mathrm{HD}$, asking whether the participant has ever had the symptom (yes or no) and, if yes, the age at which the symptom was first experienced (appendix 3, doi.org/10.5061/dryad.pk0p2ngkz). Information was available, at least in part, for 5,609 individuals. The symptoms recorded (number of individuals with data) were as follows: motor (chorea or other, consistent with HD) 5,603; cognitive impairment sufficient to affect work or daily living 5,591; apathy 5,584; depression 5,595; perseverative/obsessive behavior 5,588; irritability 5,586; violent or aggressive behavior 5,586; and psychosis 5,589. For subsequent analyses, missing data were handled using pairwise deletion to maximize the number of individuals. Typically, the rater estimate of clinical onset and initial HD-CCQ would be recorded at the first REGISTRY visit, sometimes by 1 clinician and sometimes by a clinician and another qualified staff member such as $\mathrm{HD}$ specialist nurse, depending on local clinic setup. Subsequent visits updated the $\mathrm{HD}-\mathrm{CCQ}_{i}$ we used data from the most recent clinic visit. We had data on Shoulson-Fahn disease stage at last clinic visit for 4,554 individuals $(72.1 \%$ of our study population): stage 1 (total functional capacity [TFC] 11-13; n = $890,19.5 \%$ ), stage 2 (TFC $7-10 ; n=1,278,28.1 \%$ ), stage 3 
Table 1 Association of Validated Clinical Scores With the HD Clinical Characteristics Questionnaire Symptoms and Other Covariates

\begin{tabular}{|c|c|c|c|c|c|c|c|c|}
\hline & \multicolumn{2}{|c|}{ TDS Score $(n=2,403)$} & \multicolumn{2}{|c|}{ TIS Score $(n=2,403)$} & \multicolumn{2}{|c|}{ SDMT Score $(n=3,137)$} & \multicolumn{2}{|c|}{$\begin{array}{l}\text { Stroop Interference } \\
\text { Score }(n=3,273)\end{array}$} \\
\hline & $\begin{array}{l}\text { Effect } \\
(95 \% \mathrm{CI})\end{array}$ & $p$ Value & $\begin{array}{l}\text { Effect } \\
(95 \% \mathrm{CI})\end{array}$ & $p$ Value & $\begin{array}{l}\text { Effect } \\
(95 \% \mathrm{Cl})\end{array}$ & $p$ Value & Effect $(95 \% \mathrm{CI})$ & $p$ Value \\
\hline Motor & $0.15( \pm 1.85)$ & $8.71 \times 10^{-1}$ & $0.67( \pm 1.93)$ & $4.93 \times 10^{-1}$ & $-12.37( \pm 3.90)$ & $5.62 \times 10^{-10, a}$ & $-9.34( \pm 3.76)$ & $1.19 \times 10^{-6, a}$ \\
\hline Cognitive & $0.38( \pm 0.39)$ & $5.28 \times 10^{-2}$ & $-0.41( \pm 0.40)$ & $4.53 \times 10^{-2, b}$ & $-3.52( \pm 0.81)$ & $2.28 \times 10^{-17, a}$ & $-3.41( \pm 0.76)$ & $3.29 \times 10^{-18, a}$ \\
\hline Apathy & $1.73( \pm 0.40)$ & $4.05 \times 10^{-17, a}$ & $0.48( \pm 0.42)$ & $2.36 \times 10^{-2, b}$ & $-2.70( \pm 0.83)$ & $2.37 \times 10^{-10, a}$ & $-2.15( \pm 0.79)$ & $1.00 \times 10^{-7, a}$ \\
\hline Depression & $1.49( \pm 0.40)$ & $5.67 \times 10^{-13, a}$ & $1.13( \pm 0.42)$ & $1.37 \times 10^{-7, a}$ & $-0.09( \pm 0.84)$ & $8.41 \times 10^{-1}$ & $-0.53( \pm 0.79)$ & $1.88 \times 10^{-1}$ \\
\hline POB & $-0.15( \pm 0.42)$ & $4.96 \times 10^{-1}$ & $0.04( \pm 0.44)$ & $8.70 \times 10^{-1}$ & $-1.28( \pm 0.85)$ & $3.26 \times 10^{-3, b}$ & $-1.10( \pm 0.80)$ & $7.45 \times 10^{-3, b}$ \\
\hline Irritability & $0.15( \pm 0.43)$ & $4.97 \times 10^{-1}$ & $1.82( \pm 0.45)$ & $1.99 \times 10^{-15, a}$ & $1.28( \pm 0.89)$ & $4.52 \times 10^{-3, b}$ & $1.01( \pm 0.84)$ & $1.76 \times 10^{-2, b}$ \\
\hline VAB & $0.72( \pm 0.47)$ & $2.65 \times 10^{-3, b}$ & $1.57( \pm 0.49)$ & $3.29 \times 10^{-10, a}$ & $-1.24( \pm 0.97)$ & $1.26 \times 10^{-2, b}$ & $-1.20( \pm 0.92)$ & $1.06 \times 10^{-2, b}$ \\
\hline Psychosis & $-0.45( \pm 0.68)$ & $1.98 \times 10^{-1}$ & $-0.50( \pm 0.71)$ & $1.67 \times 10^{-1}$ & $-2.53( \pm 1.38)$ & $3.38 \times 10^{-4, a}$ & $-3.18( \pm 1.28)$ & $1.07 \times 10^{-6, a}$ \\
\hline Age & $0.01( \pm 0.02)$ & $2.18 \times 10^{-1}$ & $-0.09( \pm 0.02)$ & $8.17 \times 10^{-13, a}$ & $-0.53( \pm 0.05)$ & $1.02 \times 10^{-99, a}$ & $-0.52( \pm 0.05)$ & $2.89 \times 10^{-104, a}$ \\
\hline CAG & $-0.03( \pm 0.06)$ & $3.54 \times 10^{-1}$ & $-0.21( \pm 0.07)$ & $1.17 \times 10^{-9, a}$ & $-1.56( \pm 0.14)$ & $3.97 \times 10^{-102, a}$ & $-1.25( \pm 0.13)$ & $2.38 \times 10^{-71, a}$ \\
\hline $\operatorname{Sex}(F)$ & $-0.12( \pm 0.37)$ & $5.17 \times 10^{-1}$ & $0.35( \pm 0.38)$ & $7.14 \times 10^{-2}$ & $-1.28( \pm 0.76)$ & $9.73 \times 10^{-4, a}$ & $-1.22( \pm 0.72)$ & $9.13 \times 10^{-4, a}$ \\
\hline Duration & $0.05( \pm 0.04)$ & $5.62 \times 10^{-3, b}$ & $0.02( \pm 0.04)$ & $3.08 \times 10^{-1}$ & $-0.41( \pm 0.08)$ & $4.78 \times 10^{-25, a}$ & $-0.32( \pm 0.07)$ & $4.82 \times 10^{-18, a}$ \\
\hline
\end{tabular}

Abbreviations: $\mathrm{Cl}$ = confidence interval; HD = Huntington disease; $\mathrm{POB}=$ perseverative/obsessive behavior; SDMT = Symbol-Digit Modalities Test; TDS = total depression score from the Hospital Anxiety and Depression Scale; TIS = total irritability score from Snaith Irritability Scale; VAB = violent or aggressive behavior.

For binary covariates (Clinical Characteristics Questionnaire symptoms and sex), effect is the increase/decrease in the clinical score associated with presence of that covariate. For quantitative covariates (age, CAG, duration), effect is the change in clinical score associated with an increase of 1 unit in the covariate. In addition to having a confirmed onset and pathogenic CAG length (36-93), individuals must have no comorbid diagnosis of schizophrenia, schizotypy, or schizoaffective disorder.

a Significant associations after Bonferroni correction for 4 phenotypes and 12 covariates $\left(p<1.04 \times 10^{-3}\right)$.

${ }^{\mathrm{b}}$ Nominally significant $p$ values $(p<0.05)$.

(TFC 4-6; $\mathrm{n}=969,21.3 \%)$, stage $4($ TFC $1-3 ; \mathrm{n}=1,133$, $24.9 \%)$, and stage 5 (TFC $0 ; \mathrm{n}=284,6.2 \%)$.

The Hospital Anxiety/Depression Scale (HADS) and Snaith Irritability Scale (SIS) were completed by the participant at each clinic visit and provide measures of anxiety, depression, and irritability at that specific time. We used lifetime highest total depression and total irritability scores from both the HADS and the SIS in analyses. Similarly, the Symbol-Digit Modalities Test (SDMT) and Stroop tests of cognitive ability were administered as part of the Unified Huntington's Disease Rating Scale (UHDRS) ${ }^{11}$ at each visit. The UHDRS consists of validated questionnaires, tools, and examinations related to motor, cognitive, behavioral, and functional impairments seen in HD. For the SDMT and Stroop tests, we used the total correct scores from the most recent clinic visit. Disease duration was estimated by taking the most recent visit and subtracting the clinician's estimate of disease onset. The product of short form of the Problem Behaviours Assessment (PBA-s) severity and frequency scores from the most recent clinic was used for modeling purposes.

\section{Statistical Analyses of Clinical Data}

Total depression scores from the HADS, total irritability scores from the SIS, the number of correct answers on the
SDMT, the number of correct answers on Stroop tests, or composite PBA-s scores were regressed on HD clinical characteristics data, age, CAG length, sex, and disease duration (table 1). To calculate coefficients of determination $\left(R^{2}\right.$ values, table 2), HD-CCQ age at onset data were natural log transformed. Only individuals with a known sex and a symptom onset $\geq 3$ years were considered, and a residual vs leverage plot identified 1 influential data point passing the Cook distance that was removed from all $R^{2}$ calculations. The $p$ values were calculated comparing male and female $R^{2}$ values with the Fisher transformation. ${ }^{12} \mathrm{~A} \chi^{2}$ test was used to test for differences in symptom frequency, derived from the yes/no component of the HD-CCQ between male and female participants.

Associations between binary responses in the HD-CCQ $(1=$ experienced the symptom, $0=$ symptom not experienced) and clinical covariates were tested with logistic regression. The covariates used were sex, CAG length, alcohol consumption (units per week), tobacco use (cigarettes per day), education (years of education), TFC score, and total motor score (TMS). An additional analysis regressed the type of $\mathrm{HD}$ onset defined by the clinician, coded as a binary variable, on the clinician's onset or CAG length (table e-2, doi.org/10. 5061/dryad.pk0p2ngkz). This analysis was restricted to 
Table 2 Lifetime Prevalence of Motor and Psychiatric Symptoms in Male and Female Individuals With HD

\begin{tabular}{|c|c|c|c|c|c|c|c|c|}
\hline & \multicolumn{3}{|l|}{ Male } & \multicolumn{3}{|c|}{ Female } & \multirow[b]{2}{*}{ OR $(95 \% \mathrm{Cl})$} & \multirow[b]{2}{*}{$p$ Value $\left(\chi^{2}\right)$} \\
\hline & Yes, $n$ & No, $n$ & Frequency, \% & Yes, $\mathbf{n}$ & No, $n$ & Frequency, \% & & \\
\hline Motor & 2,691 & 28 & 98.97 & 2,859 & 25 & 99.13 & $1.19(0.69-2.05)$ & $5.29 \times 10^{-1}$ \\
\hline Cognitive & 1,584 & 1,132 & 58.32 & 1,688 & 1,187 & 58.71 & $1.02(0.91-1.13)$ & $7.66 \times 10^{-1}$ \\
\hline Apathy & 1,456 & 1,259 & 53.63 & 1,495 & 1,374 & 52.11 & $0.94(0.85-1.05)$ & $2.56 \times 10^{-1}$ \\
\hline Depression & 1,582 & 1,135 & 58.23 & 2,025 & 853 & 70.36 & $1.70(1.52-1.90)$ & $2.57 \times 10^{-21, a}$ \\
\hline РОВ & 1,005 & 1,711 & 37.00 & 1,038 & 1834 & 36.14 & $0.96(0.86-1.07)$ & $5.04 \times 10^{-1}$ \\
\hline Irritability & 1,706 & 1,006 & 62.91 & 1,634 & 1,240 & 56.85 & $0.78(0.70-0.87)$ & $4.03 \times 10^{-6, a}$ \\
\hline VAB & 947 & 1769 & 34.87 & 777 & 2,100 & 27.01 & $0.69(0.62-0.77)$ & $1.99 \times 10^{-10,2}$ \\
\hline Psychosis & 319 & 2,396 & 11.75 & 325 & 2,549 & 11.31 & $0.96(0.81-1.13)$ & $6.06 \times 10^{-1}$ \\
\hline
\end{tabular}

Abbreviations: $\mathrm{Cl}=$ confidence interval; $\mathrm{HD}=$ Huntington disease; $\mathrm{OR}=$ odds ratio; $\mathrm{POB}=$ perseverative/obsessive behavior; $\mathrm{VAB}=$ violent or aggressive behavior.

Data from HD Clinical Characteristics Questionnaire at last recorded clinic visit in An Observational Study of the European Huntington's Disease Network (REGISTRY). Chi-square tests assess the difference between prevalence in male and female patients. ORs $>1$ indicate the symptom is more common in female patients; ORs < 1 indicate the symptom is more common in male patients. To be included, individuals must have a pathogenic CAG length (36-93) and confirmed clinical HD onset.

a Significant $p$ values $\left(p<6.25 \times 10^{-3}\right.$, multiple testing correction).

participants with $\mathrm{HD}$ with 36 to 59 CAGs to be consistent with figure 1 subgroups and to individuals with adult-onset $\mathrm{HD}$ ( $\geq 20$ years). We also tested whether symptom presence was associated with the length of the wild-type (6-35 CAGs) and expanded (CAG repeat length of 36-93) CAG alleles in individuals of known sex and for whom both CAG lengths were known (table e-3, doi.org/10.5061/dryad.pk0p2ngkz). Nineteen individuals with a coincident formal diagnosis of schizophrenia, schizotypal disorder, or schizoaffective disorder (ICD-10 code F20, F21 or F25) were excluded from all models, although it was not possible to formally exclude these symptoms being part of the HD phenotype. Statistical analysis used $\mathrm{R}$ (version 3.6.0; R Core Team, 2019, r-project.org/).

\section{Data Availability}

Further information and data requests should be directed to Thomas H. Massey (MasseyT1@cardiff.ac.uk). Anonymized summary data are available to qualified investigators. Furthermore, anonymized patient data are available from the EHDN on request given institutional assurance that patient confidentiality will be upheld and no attempt will be made to discover the identity of patients.

\section{Results}

\section{The Initial Manifestation of HD Varies With Age and CAG Length}

The age at onset of the first unequivocal motor features of $\mathrm{HD}$ (motor onset) has been used as a specific milestone in the natural history of $\mathrm{HD}$ in individuals, although it is only a crude measure of a progressive neuropathologic process. It has proved particularly useful in recent genetic modifier studies of $\mathrm{HD} .{ }^{13,14}$ The first psychiatric and cognitive manifestations of $\mathrm{HD}$ are more difficult to define with certainty, being less specific for $\mathrm{HD}$ and clinically indistinguishable from common coincident psychiatric diagnoses (e.g., depression), particularly in younger patients many years from predicted motor onset. The timing of the first unequivocal feature of $\mathrm{HD}$ is typically recorded retrospectively by a rating physician in observational studies such as REGISTRY according to clinical information and symptom history from patients and care partners. ${ }^{9,15,16}$ The rater also records the initial major presenting feature of a choice of 6: motor, cognitive, psychiatric, oculomotor, other, or mixed. We analyzed the initial manifestation of HD for 6,316 participants in REGISTRY, $^{9}$ including 3,083 male (48.8\%) and 3,233 female (51.2\%) participants. All participants had a confirmed genetic diagnosis of $\mathrm{HD}$ with a pathogenic $\mathrm{CAG}$ repeat length of 36 to 93 (figure e-1, doi.org/10.5061/dryad.pk0p2ngkz). The first manifestation of $\mathrm{HD}$, determined by the rating physician, varied with patient age (figure 1A and table e-1, doi.org/10.5061/dryad. pk0p2ngkz). Individuals with onset before 20 years of age, defined as juvenile $\mathrm{HD}$, were equally likely to present with motor (24.5\%), cognitive $(21.8 \%)$, or psychiatric features $(28.2 \%)$. In contrast, the initial manifestation of $\mathrm{HD}$ was more likely to be motor than psychiatric in adult-onset $\mathrm{HD}$. As age at the first manifestation increased (figure 1A and table e-2A, doi.org/10. 5061/dryad.pk0p2ngkz), motor presentations became more likely (odds ratio [OR] 1.06 per 10-year increase in onset age, 95\% confidence interval [CI] 1.04-1.07; $p=7.4 \times 10^{-22}$ ), but psychiatric presentations became less likely (OR 0.96 per 10-year increase in onset age, $95 \%$ CI 0.95-0.97; $\left.p=9.4 \times 10^{-16}\right)$. For people presenting at $>60$ years of age, more than two-thirds (68.6\%) had initial motor abnormalities, with far fewer having psychiatric $(11.5 \%)$ or cognitive $(6.7 \%)$ presentations. Next, we tested whether there was any relationship between pathogenic CAG repeat length, known to be inversely correlated with age at clinical onset, and the presenting phenotype. There was no significant relationship between CAG length (36-59 inclusive) 

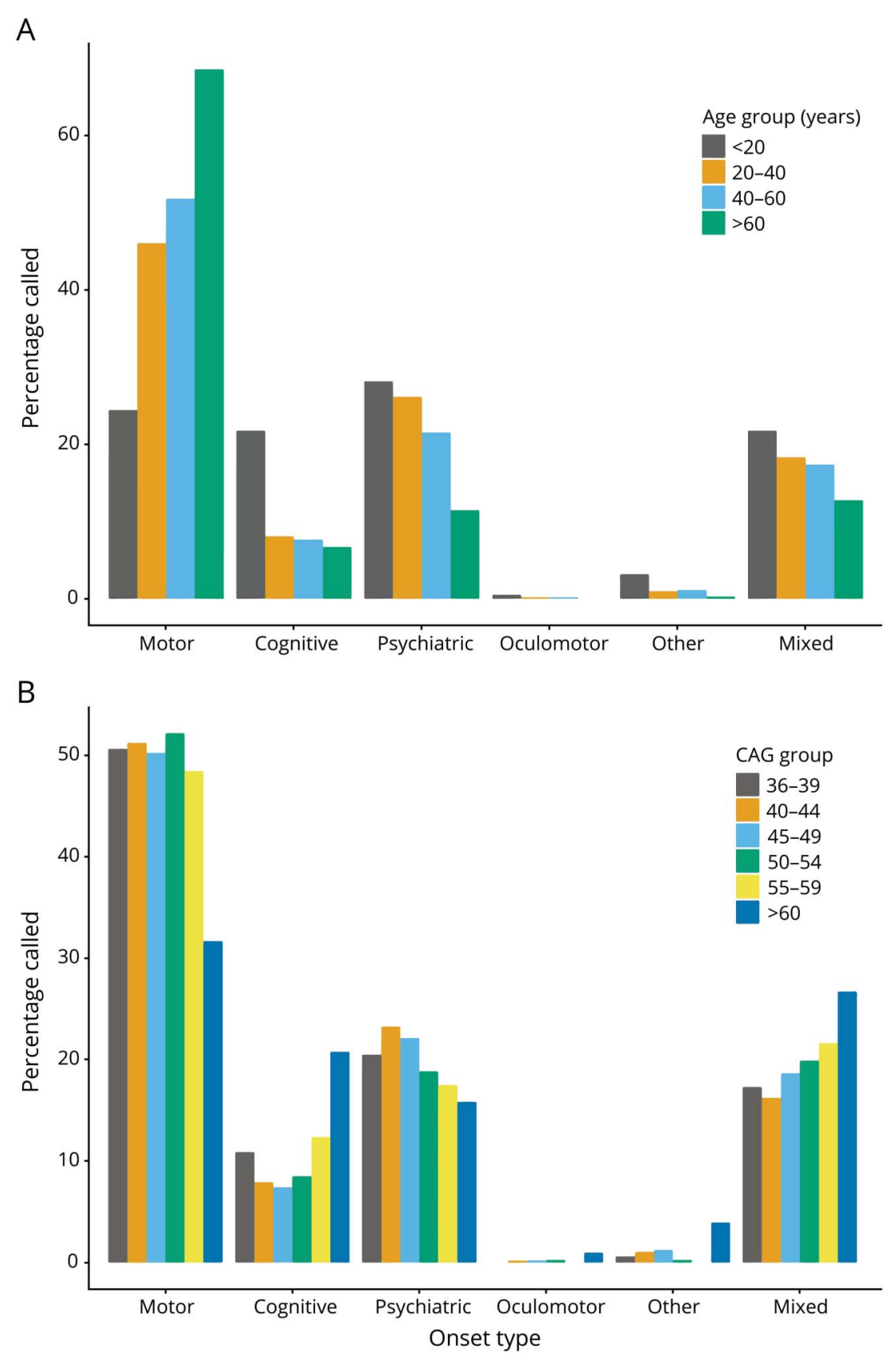

All included individuals had a pathogenic CAG length
( $36-93$ ) and confirmed Huntington disease (HD)
onset age determined by a rating clinician. (A) Fre-
quency of different onset types in 4 age groups,
chosen to show juvenile HD and then 20 -year bins
for clarity. Total $n=6,289,<20$ years $n=188,20$ to 40
years $n=2,216,40$ to 60 years $n=3,276,>60$ years $n$
$=609$. (B) Frequency of different onset types in 6
CAG length groups, chosen for clarity across the
pathogenic range. Total $n=6,289,36$ to 39 CAG $n=$
156,40 to 44 CAG $n=3,813,45$ to 49 CAG $n=1,735$,
50 to 54 CAG $n=387,55$ to 59 CAG $n=97,>60$ CAG $n$
$=101$.

and the relative proportions of motor, cognitive, and psychiatric onset cases (figure 1B and table e-2B, doi.org/10.5061/dryad. pk0p2ngkz). For the few cases with data and repeat lengths of >59 CAGs, we observed a more balanced distribution of motor, cognitive, and psychiatric presentations, mirroring the trends seen for the cases of juvenile HD.

\section{Psychiatric and Cognitive Symptoms Captured by HD-CCQ Correlate With Scores From Validated Clinical Tools}

The HD-CCQ was introduced to later versions of REGISTRY as the best retrospective way of capturing symptom data in existing HD populations. It is completed by a health care professional using information from individuals with $\mathrm{HD}$ and their care partners, present in clinic for $>93 \%$, about lifetime history and age at onset of 8 symptoms typical of HD. These symptoms are motor (compatible with HD), depression, irritability, violent or aggressive behavior, apathy, perseverative/ obsessive behavior, psychosis, and cognitive impairment sufficient to affect work or daily living. In REGISTRY, this information was updated at each annual clinic visit. In HD-CCQ, motor symptoms are not specified beyond being compatible with $\mathrm{HD}$, limiting the utility of motor data, but psychiatric and behavioral symptoms are clearly defined. 

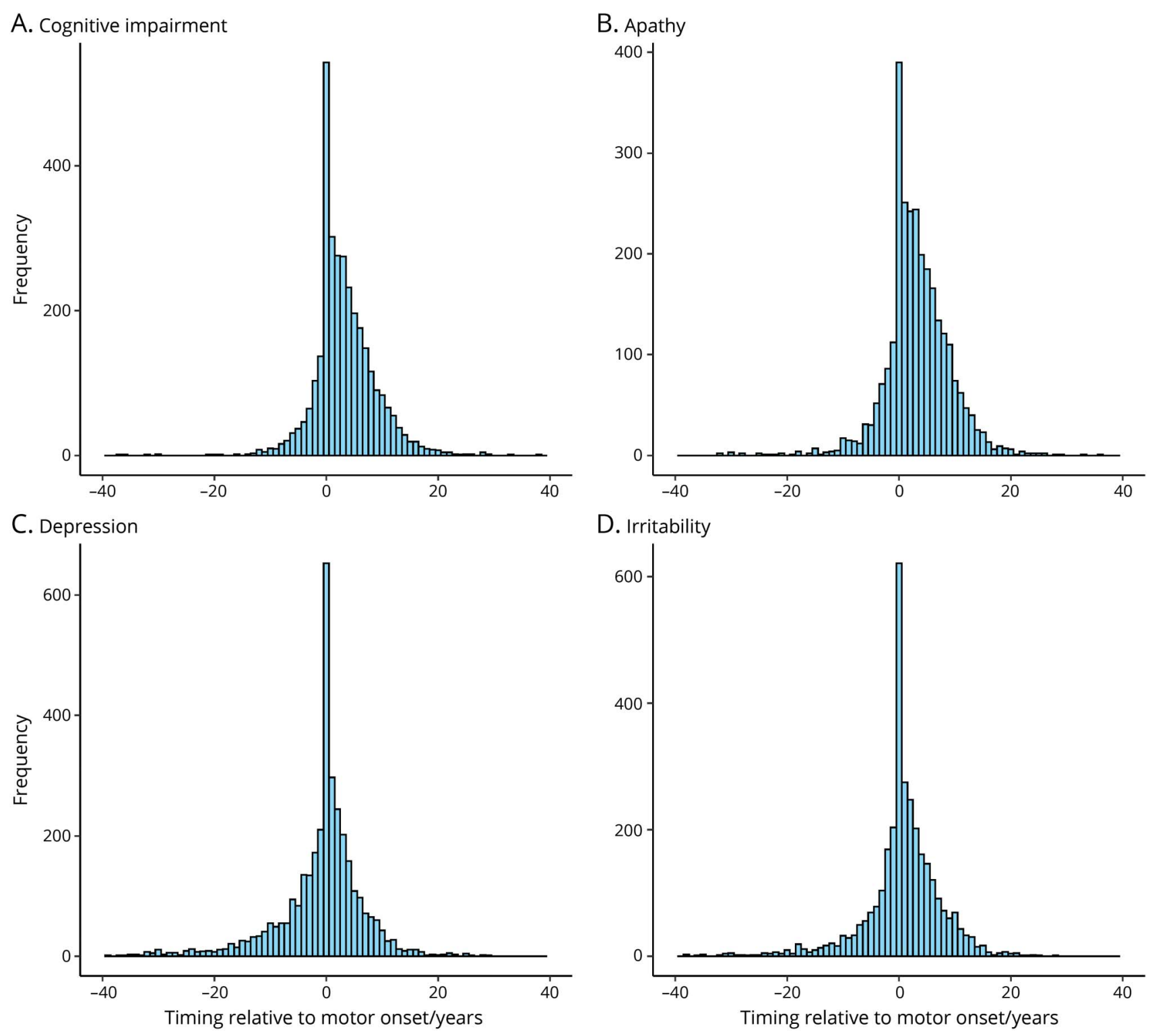

Age at onset of motor symptoms was subtracted from the age at onset of each cognitive/psychiatric symptom when present. Timings of up to \pm 40 years relative to motor onset shown. Only individuals with a rater-confirmed age at onset and CAG length (36-93) were included. Data from Huntington Disease (HD) Clinical Characteristics Questionnaire. (A) Cognitive impairment $n=3,225$; (B) apathy $n=2,852 ;(C)$ depression $n=3,495$; and (D) irritability $n=3,235$.

Because prevalence data from HD-CCQ have not been used in large analyses before, we first tested how well they correlated with validated clinical scores of depression (HADS), irritability (SIS), and cognition (SDMT and Stroop). To mitigate against potential effects of medication at certain times, we used the lifetime highest total depression and total irritability scores for each individual. For cognitive tests, we used scores at the last recorded clinic visit because these would be expected to worsen progressively and to be little affected by medication. Total depression score from HADS was significantly increased in individuals with depression recorded in HD-CCQ (increase of 1.49 units, $95 \%$ CI 1.09-1.89; $p=5.7 \times 10^{-13}$; table 1$)$. An increase in HADS score was also observed in individuals with
HD-CCQ apathy, probably because apathy, common in $\mathrm{HD}$, may be mistaken for depression by individuals and their care partners when completing the HD-CCQ. Total irritability score from SIS was significantly increased in individuals with HD-CCQ irritability (increase of 1.82 units, 95\% CI 1.37-2.27; $p=2.0 \times 10^{-15}$ ) and with violent/aggressive behavior (increase of 1.57 units, $95 \%$ CI $\left.1.08-2.06 ; p=3.3 \times 10^{-10}\right)$, as expected. Both SDMT and Stroop scores of cognitive ability were significantly decreased in individuals with cognitive impairment as recorded in HD-CCQ (reductions of 3.52 units, 95\% CI $2.71-4.33 ; p=2.3 \times 10^{-17}$ and 3.41 units, $95 \%$ CI $2.65-4.17 ; p$ $=1.4 \times 10^{-22}$, respectively). Significant associations between cognitive scores and motor and apathy symptoms were also 


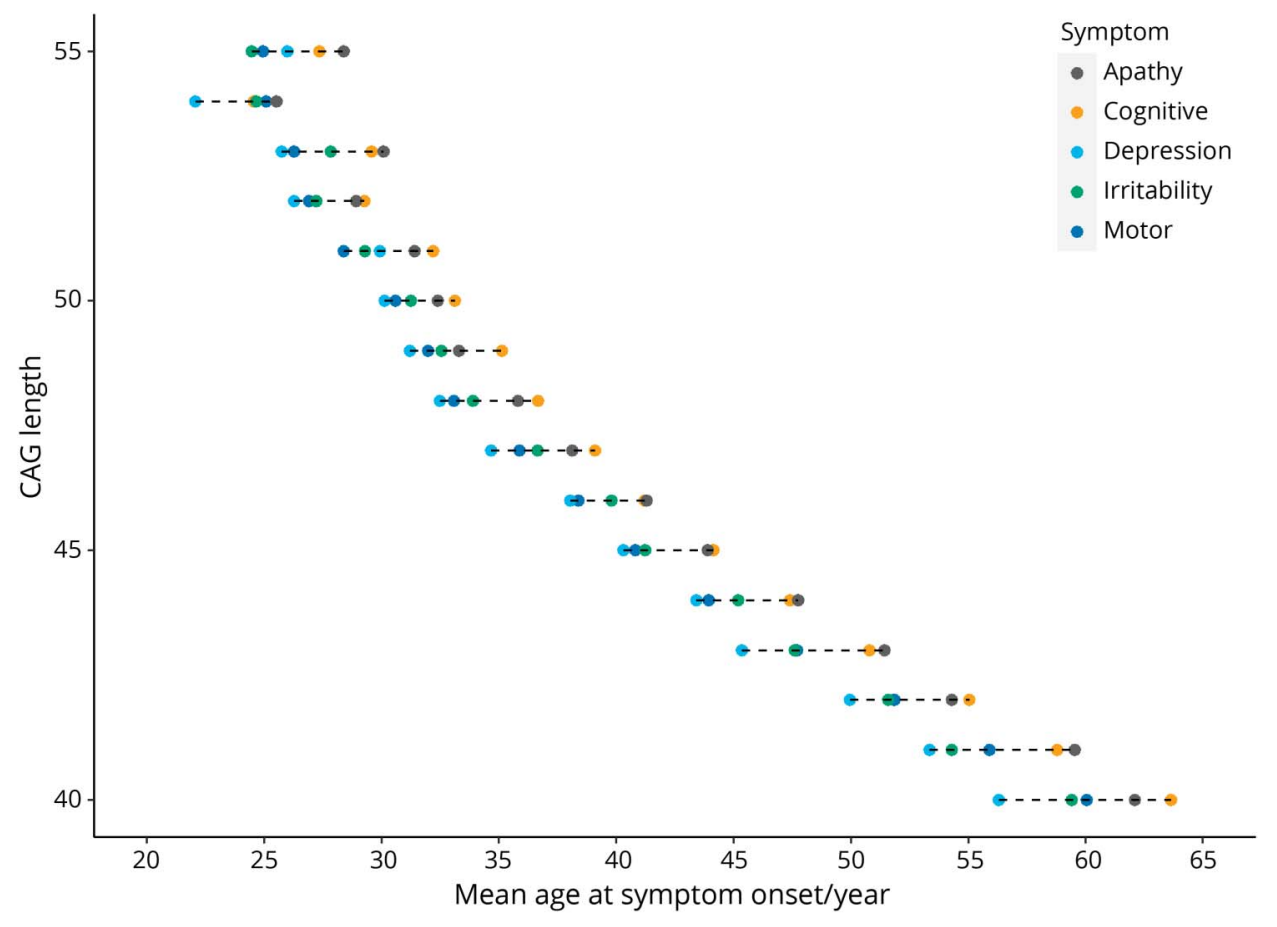

Shown are the mean ages at symptom onset as recorded by the Huntington Disease Clinical Characteristics Questionnaire for apathy $(n=2,739)$, cognitive impairment $(n=3,069)$, depression $(n=3,399)$, irritability $(n=$ $3,117)$, and motor symptoms $(\mathrm{n}=$ $4,889)$. observed. In addition, we found robust and specific associations between neuropsychiatric symptoms recorded in $\mathrm{HD}-\mathrm{CCQ}$ and their related symptoms scored with the validated PBA-s (supplemental table e-4, doi.org/10.5061/dryad.pk0p2ngkz). The specificity of the associations between HD-CCQ data and recognized clinical scales validated the use of $\mathrm{HD}-\mathrm{CCQ}$ data in subsequent analyses.

\section{Psychiatric Symptoms Are Common in HD Gene Carriers and Are Associated With CAG Repeat Length}

We next analyzed the lifetime prevalence of the 8 symptoms recorded in $\mathrm{HD}$-CCQ in 5,609 individuals with $\mathrm{HD}$ at their most recent clinic visit (table 2). The mean age at last recorded clinic visit was 53.3 years: 53.5 years for male participants with data

Table 3 Variance in Age at Onset $\left(R^{2}\right)$ Explained by Pathogenic CAG Repeat Length for 8 Symptoms in Male and Female Patients With HD

\begin{tabular}{|c|c|c|c|c|c|c|c|}
\hline & \multicolumn{2}{|l|}{ Male } & \multicolumn{2}{|l|}{ Female } & \multirow[b]{2}{*}{$p$ Value } & \multicolumn{2}{|l|}{ Both } \\
\hline & $R^{2}(95 \% \mathrm{CI})$ & No. & $R^{2}(95 \% \mathrm{Cl})$ & No. & & $R^{2}(95 \% \mathrm{Cl})$ & No. \\
\hline Motor & $0.678(0.657-0.697)$ & 2,684 & $0.649(0.628-0.670)$ & 2,844 & $5.42 \times 10^{-2}$ & $0.663(0.648-0.677)$ & 5,528 \\
\hline Cognitive & $0.610(0.579-0.639)$ & 1,570 & $0.629(0.600-0.656)$ & 1,681 & $3.80 \times 10^{-1}$ & $0.619(0.598-0.639)$ & 3,251 \\
\hline Apathy & $0.595(0.562-0.627)$ & 1,423 & $0.562(0.528-0.595)$ & 1,462 & $1.83 \times 10^{-1}$ & $0.578(0.554-0.601)$ & 2,885 \\
\hline Depression & $0.412(0.374-0.449)$ & 1,551 & $0.351(0.318-0.385)$ & 1,994 & $3.50 \times 10^{-2, a}$ & $0.375(0.350-0.400)$ & 3,545 \\
\hline РOB & $0.539(0.496-0.581)$ & 973 & $0.440(0.394-0.485)$ & 1,016 & $3.67 \times 10^{-3, b}$ & $0.489(0.457-0.52)$ & 1,989 \\
\hline Irritability & $0.463(0.428-0.498)$ & 1,670 & $0.547(0.513-0.579)$ & 1,601 & $1.25 \times 10^{-3, b}$ & $0.503(0.478-0.527)$ & 3,271 \\
\hline VAB & $0.479(0.431-0.524)$ & 927 & $0.478(0.426-0.528)$ & 761 & $9.79 \times 10^{-1}$ & $0.477(0.442-0.511)$ & 1,688 \\
\hline Psychosis & $0.401(0.316-0.484)$ & 312 & $0.424(0.340-0.504)$ & 318 & $7.29 \times 10^{-1}$ & $0.411(0.351-0.469)$ & 630 \\
\hline
\end{tabular}

Abbreviations: $\mathrm{Cl}$ = confidence interval; $\mathrm{HD}=$ Huntington disease; $\mathrm{POB}=$ perseverative/obsessive behavior; $\mathrm{VAB}=$ violent or aggressive behavior.

Ages at onset were logarithmically transformed and plotted against CAG length. The $p$ values test differences between male and female $R^{2}$. Individuals had to have a clinical onset of HD, a known sex and a pathogenic CAG length (36-93) to be included.

${ }^{a}$ Nominally significant $p$ values $(p<0.05)$

b Significant $p$ values ( $p<6.25 \times 10^{-3}$; multiple testing correction). 
Table 4 Psychiatric and Cognitive Symptoms Are Associated With Reduced Functional Capacity

\begin{tabular}{|c|c|c|c|c|c|c|c|c|}
\hline & \multicolumn{2}{|l|}{ Motor $(n=1,644)$} & \multicolumn{2}{|c|}{ Cognitive $(n=1,644)$} & \multicolumn{2}{|c|}{ Apathy $(n=1,643)$} & \multicolumn{2}{|c|}{ Depression $(n=1,645)$} \\
\hline & OR $(95 \% \mathrm{Cl})$ & $p$ Value & OR $(95 \% \mathrm{Cl})$ & $p$ Value & OR $(95 \% \mathrm{Cl})$ & $p$ Value & OR $(95 \% \mathrm{Cl})$ & $p$ Value \\
\hline $\operatorname{Sex}(F)$ & $0.49(0.14-1.66)$ & $2.51 \times 10^{-1}$ & $1.20(0.97-1.49)$ & $9.75 \times 10^{-2}$ & $1.07(0.87-1.31)$ & $5.13 \times 10^{-1}$ & $1.77(1.44-2.17)$ & $6.98 \times 10^{-8, a}$ \\
\hline CAG & $0.95(0.83-1.10)$ & $5.10 \times 10^{-1}$ & $1.01(0.98-1.03)$ & $6.64 \times 10^{-1}$ & $0.99(0.96-1.01)$ & $2.32 \times 10^{-1}$ & $0.96(0.93-0.98)$ & $1.32 \times 10^{-4, a}$ \\
\hline Duration & $0.91(0.82-1.01)$ & $8.32 \times 10^{-2}$ & $1.00(0.98-1.03)$ & $6.99 \times 10^{-1}$ & $1.00(0.98-1.02)$ & $8.96 \times 10^{-1}$ & $1.03(1.01-1.05)$ & $1.10 \times 10^{-2, b}$ \\
\hline Alcohol & $1.00(0.93-1.08)$ & $9.61 \times 10^{-1}$ & $1.02(1.01-1.04)$ & $8.78 \times 10^{-3, b}$ & $1.00(0.99-1.02)$ & $5.56 \times 10^{-1}$ & $0.99(0.98-1.01)$ & $2.66 \times 10^{-1}$ \\
\hline Tobacco & $1.10(0.96-1.26)$ & $1.54 \times 10^{-1}$ & 1.01 (0.99-1.02) & $3.00 \times 10^{-1}$ & $1.02(1.00-1.03)$ & $4.94 \times 10^{-3, b}$ & $1.02(1.01-1.03)$ & $8.14 \times 10^{-4, b}$ \\
\hline Education & $0.89(0.75-1.06)$ & $1.97 \times 10^{-1}$ & $1.01(0.98-1.05)$ & $4.03 \times 10^{-1}$ & $0.98(0.95-1.01)$ & $2.02 \times 10^{-1}$ & $0.99(0.96-1.02)$ & $5.83 \times 10^{-1}$ \\
\hline TFC & $1.05(0.75-1.46)$ & $7.85 \times 10^{-1}$ & $0.78(0.74-0.81)$ & $1.58 \times 10^{-25, a}$ & $0.87(0.84-0.91)$ & $1.14 \times 10^{-9, a}$ & $0.90(0.86-0.94)$ & $7.30 \times 10^{-6, a}$ \\
\hline TMS & $1.17(1.08-1.27)$ & $7.81 \times 10^{-5, a}$ & $1.00(0.99-1.00)$ & $2.67 \times 10^{-1}$ & $1.00(0.99-1.00)$ & $2.59 \times 10^{-1}$ & $0.98(0.98-0.99)$ & $2.59 \times 10^{-5, a}$ \\
\hline
\end{tabular}

Abbreviations: $\mathrm{Cl}$ = confidence interval; $\mathrm{OR}=$ odds ratio; $\mathrm{POB}=$ perseverative/obsessive behavior; TFC = total functional capacity; $\mathrm{TMS}=$ total motor score; $\mathrm{VAB}=$ violent or aggressive behavior. Multiple logistic regression using binary Huntington Disease Clinical Characteristics Questionnaire data for 8 symptoms $(0=$ no symptom; 1 = reported symptom) and clinical covariates. With the exception of sex, the OR indicates the effect on the outcome probability associated with an increase of 1 unit in the covariate. In addition to having a confirmed onset and pathogenic CAG length (36-93), individuals must have no comorbid diagnosis of schizophrenia, schizotypy, or schizoaffective disorder.

${ }^{a}$ Significant associations after Bonferroni correction for 8 symptoms and 8 covariates $\left(p<7.81 \times 10^{-4}\right)$.

${ }^{\mathrm{b}}$ Nominally significant associations $(p<0.05)$.

(range 10.4-92.6 years; $\mathrm{n}=2,569$ ) and 53.2 years for female participants (range 7.9-90.2 years; $\mathrm{n}=2,698$ ). Almost all (>99\%) had experienced motor symptoms compatible with $\mathrm{HD}$, indicating why motor abnormalities remain the diagnostic standard for clinical onset of HD. Although motor symptoms are not defined explicitly in $\mathrm{HD}-\mathrm{CCQ}$, contemporaneous data from UHDRS showed that $96.8 \%$ of our study population had chorea, along with variable amounts of incoordination, dystonia, and rigidity. In $\mathrm{HD}$ gene carriers, these motor symptoms are likely to be specific manifestations of $\mathrm{HD}$. The next most prevalent symptom was depression, occurring in $64.5 \%$ of individuals with $\mathrm{HD}$, with significantly more female patients affected than male patients (70.4\% vs $58.2 \%$; OR $1.70,95 \%$ CI $1.52-1.90 ; p=2.6 \times$ $10^{-21}$ ). Cognitive impairment sufficient to affect work or activities of daily living, apathy, and irritability were also each observed in more than half of our HD population. Cognitive impairment and apathy were equally likely in male and female participants, but significantly more irritability was observed in male participants ( $62.9 \%$ vs $56.9 \%$, OR $0.78,95 \%$ CI $0.70-0.87$; $\left.p=4.0 \times 10^{-6}\right)$. An excess of violent or aggressive behavior was also observed in the male group ( $34.9 \%$ vs $27.0 \%$, OR $0.69,95 \%$ CI $\left.0.62-0.77 ; p=2.0 \times 10^{-10}\right)$. Psychosis was the least prevalent of the 8 recorded symptoms, although this was still observed in $>11 \%$ of individuals with $\mathrm{HD}$ with no significant difference in prevalence between male and female participants.

There was a strong inverse correlation between pathogenic CAG repeat length (40-55 CAG inclusive) and mean age at symptom onset for all symptoms analyzed (figure 2). We found no effect of wild-type CAG allele length on any symptom onset and no any significant statistical interaction between expanded and wild-type repeat lengths (table e-3, doi.org/10.5061/dryad.pk0p2ngkz). Pathogenic CAG length explained $66.3 \%$ of the variance in age at onset of motor symptoms, in line with previous estimates, ${ }^{2,3,17-23}$ but also between $37.5 \%$ and $61.9 \%$ of the variance in onset of each of the psychiatric symptoms analyzed (table 2). Depression had the weakest association with CAG repeat length $\left(R^{2}=\right.$ $37.5 \%)$. CAG length accounted for significantly more of the variance in age at onset of perseverative/obsessive behavior in male participants $\left(p=3.7 \times 10^{-3}\right.$; table 2$)$ and irritability in female participants $\left(p=1.3 \times 10^{-3}\right)$.

\section{Timing of Motor and Psychiatric Symptoms in HD Gene Carriers Varies With Symptom Type and CAG Length}

Given that motor onset is often used as a specific milestone in the natural history of $\mathrm{HD}$, we investigated the timing of each of the 7 psychiatric/cognitive symptoms relative to the age at first motor symptoms recorded in HD-CCQ (figure 2 ). The differences in ages between first motor symptoms and each of the psychiatric symptoms were approximately normally distributed, with a wide range of at least \pm 20 years in each case (figure 2 and figure e-2, doi.org/10.5061/dryad. pk0p2ngkz). In those patients reporting depression, onset occurred before motor symptoms in 39.2\% ( $n=1,369$ of 3,495 ). For patients with irritability, onset occurred before motor symptoms in $30.8 \% \quad(\mathrm{n}=996$ of 3,235). Perseverative/obsessive behavior tended to occur later in the disease course, after motor symptoms, as did psychosis, although numbers were smaller. Cognitive impairment and apathy had the most positively skewed distributions, with onset occurring after motor onset in 2,179 of 3,225 (67.6\%) and 1,981 of $2,852(69.5 \%)$ of individuals, respectively. Overall, $42.4 \%$ of patients with HD ( $n=2,140$ of 5,042$)$ reported at least 1 psychiatric or cognitive symptom in advance of motor symptoms, with a further $22.3 \%$ ( $n=1,126$ of 5,042 ) reporting at least 1 of these symptoms at the same time as motor abnormalities. 
Table 4 (continued)

\begin{tabular}{|c|c|c|c|c|c|c|c|}
\hline \multicolumn{2}{|l|}{ POB (n = 1,641) } & \multicolumn{2}{|c|}{ Irritability $(n=1,645)$} & \multicolumn{2}{|l|}{ VAB $(n=1,645)$} & \multicolumn{2}{|c|}{ Psychosis $(n=1,642)$} \\
\hline OR $(95 \% \mathrm{CI})$ & $p$ Value & OR $(95 \% \mathrm{CI})$ & $p$ Value & OR $(95 \% \mathrm{CI})$ & $p$ Value & OR $(95 \% \mathrm{CI})$ & $p$ Value \\
\hline $1.07(0.86-1.32)$ & $5.68 \times 10^{-1}$ & $0.75(0.61-0.92)$ & $5.36 \times 10^{-3, b}$ & $0.75(0.60-0.94)$ & $1.27 \times 10^{-2, b}$ & $0.81(0.57-1.14)$ & $2.23 \times 10^{-1}$ \\
\hline $1.00(0.97-1.02)$ & $6.93 \times 10^{-1}$ & $0.99(0.97-1.01)$ & $4.74 \times 10^{-1}$ & $1.00(0.98-1.02)$ & $9.42 \times 10^{-1}$ & $0.99(0.95-1.02)$ & $4.84 \times 10^{-1}$ \\
\hline $1.03(1.00-1.05)$ & $1.68 \times 10^{-2, b}$ & $1.03(1.01-1.05)$ & $6.84 \times 10^{-3, b}$ & $1.04(1.02-1.06)$ & $9.10 \times 10^{-4, b}$ & $1.02(0.98-1.05)$ & $3.47 \times 10^{-1}$ \\
\hline $1.00(0.99-1.02)$ & $5.14 \times 10^{-1}$ & $1.01(0.99-1.02)$ & $4.79 \times 10^{-1}$ & $1.00(0.99-1.01)$ & $9.29 \times 10^{-1}$ & $1.02(1.00-1.04)$ & $3.35 \times 10^{-2, b}$ \\
\hline $1.01(1.00-1.02)$ & $2.04 \times 10^{-1}$ & $1.02(1.01-1.03)$ & $1.02 \times 10^{-4, a}$ & $1.02(1.01-1.03)$ & $2.08 \times 10^{-3, b}$ & $1.00(0.98-1.02)$ & $8.38 \times 10^{-1}$ \\
\hline $1.00(0.97-1.03)$ & $8.21 \times 10^{-1}$ & $1.00(0.97-1.03)$ & $8.44 \times 10^{-1}$ & $0.99(0.95-1.02)$ & $3.69 \times 10^{-1}$ & $0.92(0.88-0.97)$ & $2.24 \times 10^{-3, b}$ \\
\hline $0.89(0.85-0.93)$ & $1.10 \times 10^{-6, a}$ & $0.93(0.89-0.97)$ & $8.83 \times 10^{-4, b}$ & $0.88(0.84-0.93)$ & $2.07 \times 10^{-7, a}$ & $0.83(0.77-0.89)$ & $3.33 \times 10^{-7, a}$ \\
\hline 0.99 (0.99-1.00) & $6.09 \times 10^{-2}$ & $0.99(0.98-1.00)$ & $7.46 \times 10^{-3, b}$ & $0.99(0.99-1.00)$ & $7.49 \times 10^{-2}$ & $0.99(0.98-1.00)$ & $1.47 \times 10^{-1}$ \\
\hline
\end{tabular}

We next assessed whether there were any patterns in the mean ages at onset of the different symptoms when plotted by CAG repeat length (figure 3 ). Some consistent relationships between symptoms were observed. Depression usually had the youngest mean age at onset, followed by motor impairment and then apathy and cognitive impairment as the latest symptoms. Mean age at onset of irritability preceded that of motor onset at shorter repeat lengths (40-43 CAGs, inclusive) but tended to follow it at longer repeat lengths (44-53 CAGs, inclusive). The mean difference in years from onset of first symptom to last decreased with CAG repeat length from $\approx 8$ years for 40 repeats to 4 years for 55 repeats (figure 3).

\section{Cognitive and Psychiatric Symptoms Are Significantly Associated With Reduced Functional Capacity}

To assess whether psychiatric, cognitive, or motor symptoms were associated with altered functional abilities, we used multiple logistic regression (table 4). This analysis incorporated sex, pathogenic CAG length, duration of disease from clinical onset to last clinic visit, alcohol consumption, tobacco use, educational attainment, TFC score, and TMS as predictors of the presence/ absence of each HD-CCQ symptom. The presence of any of the psychiatric or cognitive symptoms was significantly associated with lower TFC, an indication of impaired ability to work, manage personal finances, and function independently. Cognitive impairment was most significantly associated with reduced TFC (OR per 1-unit decrease in TFC 1.28, 95\% CI 1.23-1.35; $p$ $\left.=1.6 \times 10^{-25}\right)$. Depression was significantly associated with lower TMSs (indicating fewer motor symptoms or signs), fitting with its prevalence early in the disease course. Finally, significant associations were observed between depression and female sex (OR 1.77, 95\% CI 1.44-2.17; $p=7.0 \times 10^{-8}$ ) and tobacco use and irritability (OR per 1 extra cigarette per day $1.02,95 \% \mathrm{CI}$ $\left.1.01-1.03 ; p=1.0 \times 10^{-4}\right)$. Although not reaching strict criteria for significance after correction for multiple tests, associations were also found between male sex and irritability (OR 0.75, 95\% CI $0.61-0.92 ; p=5.4 \times 10^{-3}$ ) and lower educational attainment and psychosis (OR per 1 extra year of education $0.92,95 \%$ CI $\left.0.88-0.97 ; p=2.2 \times 10^{-3}\right)$.

\section{Discussion}

In this large study of $>6,000$ patients, we have shown that the initial manifestation of $\mathrm{HD}$, as determined retrospectively by an expert rater, varies significantly with age. Late presentations ( $>60$ years) are usually associated with motor abnormalities, whereas early presentations $(<20$ years; juvenile HD) are associated with a wider range of motor, cognitive, and psychiatric abnormalities (figure 1A). These results extend prior studies that have shown that motor presentation of $\mathrm{HD}$ is common in late-onset disease $\left(65.5 \%\right.$ of an earlier REGISTRY cohort $\left.^{24}\right)$, with more variable presentations in juvenile $\mathrm{HD} .^{25,26}$ Approximately $20 \%$ of patients with $\mathrm{HD}$ present with rater-determined psychiatric features, in line with previous findings (table e-1, doi. org/10.5061/dryad.pk0p2ngkz). ${ }^{9}$ Cognitive onset of HD might be underreported in older age groups because it is regarded as coincident age-related change. Our results show that there is little relationship between pathogenic CAG repeat length and onset type in adult-onset HD (figure 1B), despite both being associated with age at clinical onset. These data fit a model in which age at clinical onset is driven primarily by CAG repeat length but modified by environmental factors and variants at other genomic loci. $^{14,23,27,28}$ The age and physiology of the brain at clinical onset subsequently determine the types of symptoms that become manifest.

The HD-CCQ captures quantitative information not available elsewhere on symptom prevalence and timing in the $\mathrm{HD}$ population. Before its introduction in REGISTRY, age at first motor symptoms was not routinely recorded for all patients with $\mathrm{HD}$. HD-CCQ provides particular insight into neuropsychiatric symptoms but is not designed to capture the subtle early motor or cognitive signs found in prospective studies. ${ }^{7,8}$ Because it relies on retrospective reporting by patients and care partners, the HD-CCQ is necessarily coarse, although the data 
it generates correlate well with more precise measures of depression, irritability, and cognition (table 1). Cognitive impairment measured by SDMT or Stroop tests correlated most strongly with lifetime history of cognitive impairment in HD-CCQ, as expected, but also showed significant correlations with motor symptoms and apathy. These results fit with other studies showing that these symptoms track together in the disease trajectory. ${ }^{29,30}$ There was also a significant association between cognitive impairment and psychosis, which fits the cognitive deficits observed in schizophrenia. ${ }^{31}$ Conversely, validated depression and irritability scores correlated well with their respective prevalence data from HD-CCQ but were not associated with motor or cognitive impairment (table 1).

Almost all patients with HD have specific motor abnormalities consistent with HD during their disease course (table 2). Psychiatric and cognitive symptoms are also very common (table 2 ), much more prevalent than in non-HD populations, $5,10,32,33$ and likely are underestimated due to pathologic unawareness of these traits by patients with $\mathrm{HD} .{ }^{34}$ However, clinically, it is currently impossible to distinguish between symptoms arising as a result of the HD mutation and those arising from primary psychiatric disorders, particularly in younger premanifest patients in whom diseases such as depression are common. ${ }^{35}$ Furthermore, environmental effects on mental health such as living in a family with HD should not be overlooked. Therefore, nonmotor symptoms should not be used to make a clinical diagnosis of $\mathrm{HD}$; doing so could even cause harm in vulnerable individuals with psychiatric symptoms. Future studies of psychiatric and cognitive symptoms and signs in $\mathrm{HD}$ gene carriers against gene-negative community controls might help define an $\mathrm{HD}$-specific neuropsychiatric phenotype that would enable more confident attribution of early abnormalities to $\mathrm{HD}$.

The age at onset of each symptom recorded by HD-CCQwas inversely correlated with CAG length (figure 3), with motor symptoms best correlated (table 3). Depression was least correlated $\left(R^{2}=37.5 \%\right)$, likely reflecting the high prevalence of the symptom in the general population independently of $\mathrm{HD}$ and the lack of use of universal diagnostic criteria. These data are consistent with previous reports showing that CAG length accounts for $47 \%$ to $72 \%$ of the variance in age at motor onset of $\mathrm{HD}^{36}$ but contradict previous studies that reported no correlation between CAG repeat length and psychiatric symptoms. ${ }^{37-40}$ However, these studies were small and often examined incident psychiatric symptoms, which can fluctuate over time, rather than lifetime history as here. Accurate CAG tract sizing will improve the accuracy of correlations between repeat length and symptoms. ${ }^{14,41,42}$

Despite considerable variation in the timing of psychiatric and motor symptoms, there are some conserved patterns (figures 2 and 3). Depression and, less often, irritability can precede motor symptoms by many years. Conversely, apathy and cognitive impairment tend to occur after motor symptoms, although patients do recognize and report these symptoms less readily than depression or irritability. Overall, the HD-CCQ data show that
$64.8 \%$ of our $\mathrm{HD}$ population $(n=3,266$ of 5,042$)$ reported at least 1 psychiatric or cognitive symptom by the time of the first motor symptoms. This is a much higher figure than previously reported and based on clinician estimates of first HD manifestation (figure 1), ${ }^{9}$ most likely because it is difficult to confidently attribute early psychiatric symptoms to HD. The overlap between $\mathrm{HD}$ and psychiatric disorders has been demonstrated by the recent finding that polygenic risk scores for psychiatric diseases, particularly depression and schizophrenia, are associated with increased risk of corresponding psychiatric symptoms in HD. ${ }^{29}$ This suggests that the expanded HTT CAG repeat might lower the genetic threshold for manifestation of typical psychiatric symptoms. ${ }^{29}$ In agreement, we found the expected relationships between female sex and depression and male sex and irritability in our cohort (table 4). The nominally significant negative association of psychosis in $\mathrm{HD}$ with educational level (table 4) also corroborates work showing that higher levels of education are associated with decreased schizophrenia risk. ${ }^{43}$

We acknowledge several potential limitations of these data. They are retrospective, subject to recall bias, and cross-sectional. Furthermore, HD-CCQ data depend on the interpretation of questions. For example, motor symptoms are not explicitly defined, so although $96.8 \%$ of our population had chorea, this was not documented in HD-CCQ. Future iterations might usefully subdivide motor symptoms into (1) fidgety or jerky involuntary movements (chorea) and (2) other HD-related movement problems such as unsteadiness, stiffness, or trouble with fine movements. Our analyses are based on data from the most recent clinic visit, which is at different points of the disease course in different individuals. We controlled for this by using disease duration, the time between first onset and last clinic visit, as a covariate in analyses. The use of psychoactive medications is found in up to $60 \%$ of patients with $\mathrm{HD}$ and might confound motor and neuropsychiatric phenotypes. ${ }^{9,44}$ Of drugs prescribed for chorea, tetrabenazine can induce depression, and antipsychotics can reduce irritability. They also suppress motor manifestations, which might affect the TMSs used here as a covariate (table 4). It is hard to control for these effects. Drugs prescribed to treat symptoms once they are present will not influence symptom onset data. We used worst-ever depression and irritability scores when validating the use of HD-CCQ to mitigate against the effects of medication prescribed at certain times.

Previous prospective studies of phenotype in HD such as Neurobological Predictors of Huntington's Disease (PREDICT-HD) and TRACK-HD (an observational study of pre-manifest and early stage HD) have shown subtle early reductions in psychiatric and cognitive function years in advance of clinical onset. ${ }^{7,8}$ The HD-CCQ accesses retrospective data from large existing populations of patients with manifest HD and shows similar trends. Because the HD-CCQ is part of ongoing global longitudinal observational studies such as ENROLL-HD, future analyses of larger populations will be possible and of benefit. The presence of psychiatric and cognitive symptoms in $\mathrm{HD}$ gene carriers is associated with significantly reduced functional capacity, emphasizing the 
importance of early recognition and management of these symptoms. ${ }^{8,45}$ Although recent models of $\mathrm{HD}$ staging and progression do not directly include psychiatric and cognitive symptoms, ${ }^{46-48}$ work is underway to include them in ongoing observational studies and clinical trials to improve the accuracy of clinical outcome measures.

\section{Acknowledgment}

The authors thank all the patients who contributed data to this research.

\section{Study Funding}

B. McAllister was supported by a $\mathrm{PhD}$ studentship from Cardiff University School of Medicine. J.F. Gusella and M.E. MacDonald received support from NIH grant NS091161 and from the CHDI Foundation, Inc. J.-M. Lee. received support from grant R01NE-105709. A.E. Rosser received support from MRC, Wellcome Trust, Campaign for Alzheimer's Research in Europe, Horizon 2020, JPND, and Health and Care Research Wales. L. Jones, N.M. Williams, and P. Holmans were supported by a Medical Research Council (MRC) Center grant (MR/L010305/1). T.H. Massey was supported by a Welsh Clinical Academic Track Fellowship, an MRC Clinical Training Fellowship (MR/P001629/1), and a Patrick Berthoud Charitable Trust Fellowship through the Association of British Neurologists.

\section{Disclosure}

J.F. Gusella has been a Scientific Advisory Board member and has a financial interest in Triplet Therapeutics, Inc. His NIHfunded project is using genetic and genomic approaches to uncover other genes that significantly influence when diagnosable symptoms emerge and how rapidly they worsen in HD. The company is developing new therapeutic approaches to address triplet repeat disorders such HD, myotonic dystrophy, and spinocerebellar ataxias. His interests were reviewed and are managed by Massachusetts General Hospital and Partners HealthCare in accordance with their conflict of interest policies. G.B. Landwehrmeyer reports fees for consulting services, advisory board functions, clinical trial services, and/or lectures from Allergan, Alnylam, Amarin, AOP Orphan Pharmaceuticals AG, Bayer Pharma AG, CHDI Foundation, GlaxoSmithKline, Hoffmann-LaRoche, Ipsen, ISIS Pharma, Lundbeck, Neurosearch Inc, Medesis, Medivation, Medtronic, NeuraMetrix, Novartis, Pfizer, Prana Biotechnology, Sangamo/Shire, Siena Biotech, Temmler Pharma $\mathrm{GmbH}$, and Teva Pharmaceuticals. He has received research grant support from the CHDI Foundation, the Bundesministerium für Bildung und Forschung, the Deutsche Forschungsgemeinschaft, and the European Commission (EUFP7, JPND). His study site Ulm has received compensation in the context of the observational ENROLL-HD Study, TEVA, ISIS, Hoffmann-Roche, and the Gossweiler Foundation. He receives royalties from the Oxford University Press and is employed by the State of Baden-Württemberg at the University of Ulm. A.E. Rosser is chair of the EHDN executive committee and global principal investigator for Triplet
Therapeutics. L. Jones is a member of the scientific advisory boards of LoQus23 Therapeutics and Triplet Therapeutics and has received funding from CHDI. T.H. Massey is an associate member of the scientific advisory board of LoQus23 Therapeutics. B. McAllister, J.-M. Lee, M.E. MacDonald, M. Orth, N.M. Williams, and P. Holmans have nothing to disclose. Go to Neurology.org/N for full disclosures.

\section{Publication History}

Received by Neurology July 31, 2020. Accepted in final form February 12, 2021.

Appendix Authors

\begin{tabular}{|c|c|c|}
\hline Name & Location & Contribution \\
\hline $\begin{array}{l}\text { Branduff } \\
\text { McAllister, BSc, } \\
\text { PhD }\end{array}$ & $\begin{array}{l}\text { Cardiff University, } \\
\text { UK }\end{array}$ & $\begin{array}{l}\text { Organized data; designed } \\
\text { and executed statistical } \\
\text { analyses; wrote first paper } \\
\text { draft; reviewed and } \\
\text { critiqued the manuscript }\end{array}$ \\
\hline $\begin{array}{l}\text { James F. Gusella, } \\
\text { PhD }\end{array}$ & $\begin{array}{l}\text { Massachusetts } \\
\text { General Hospital, } \\
\text { Boston }\end{array}$ & $\begin{array}{l}\text { Reviewed and critiqued the } \\
\text { manuscript }\end{array}$ \\
\hline $\begin{array}{l}\text { G. Bernhard } \\
\text { Landwehrmeyer, } \\
\text { MD, PhD }\end{array}$ & $\begin{array}{l}\text { University of Ulm, } \\
\text { Germany }\end{array}$ & $\begin{array}{l}\text { Reviewed and critiqued } \\
\text { manuscript }\end{array}$ \\
\hline $\begin{array}{l}\text { Jong-Min Lee, } \\
\text { PhD }\end{array}$ & $\begin{array}{l}\text { Massachusetts } \\
\text { General Hospital, } \\
\text { Boston }\end{array}$ & $\begin{array}{l}\text { Reviewed and critiqued } \\
\text { manuscript }\end{array}$ \\
\hline $\begin{array}{l}\text { Marcy E. } \\
\text { MacDonald, PhD }\end{array}$ & $\begin{array}{l}\text { Massachusetts } \\
\text { General Hospital, } \\
\text { Boston }\end{array}$ & $\begin{array}{l}\text { Reviewed and critiqued } \\
\text { manuscript }\end{array}$ \\
\hline $\begin{array}{l}\text { Michael Orth, } \\
\text { MD, PhD }\end{array}$ & $\begin{array}{l}\text { Swiss Huntington's } \\
\text { disease Centre, } \\
\text { Bern, Switzerland }\end{array}$ & $\begin{array}{l}\text { Reviewed and critiqued } \\
\text { manuscript }\end{array}$ \\
\hline $\begin{array}{l}\text { Anne E. Rosser, } \\
\text { MB BChir, FRCP, } \\
\text { PhD }\end{array}$ & $\begin{array}{l}\text { Cardiff University, } \\
\text { UK }\end{array}$ & $\begin{array}{l}\text { Reviewed and critiqued } \\
\text { manuscript }\end{array}$ \\
\hline $\begin{array}{l}\text { Nigel M. Williams, } \\
\text { BSc, PhD }\end{array}$ & $\begin{array}{l}\text { Cardiff University, } \\
\text { UK }\end{array}$ & $\begin{array}{l}\text { Reviewed and critiqued } \\
\text { manuscript }\end{array}$ \\
\hline $\begin{array}{l}\text { Peter Holmans, } \\
\text { BA, PhD }\end{array}$ & $\begin{array}{l}\text { Cardiff University, } \\
\text { UK }\end{array}$ & $\begin{array}{l}\text { Designed and } \\
\text { conceptualized study; } \\
\text { designed and critiqued } \\
\text { statistical analyses; } \\
\text { reviewed and critiqued } \\
\text { manuscript }\end{array}$ \\
\hline $\begin{array}{l}\text { Lesley Jones, BSc, } \\
\text { PhD }\end{array}$ & $\begin{array}{l}\text { Cardiff University, } \\
\text { UK }\end{array}$ & $\begin{array}{l}\text { Designed and } \\
\text { conceptualized study; wrote } \\
\text { first paper draft; reviewed } \\
\text { and critiqued manuscript }\end{array}$ \\
\hline $\begin{array}{l}\text { Thomas H. } \\
\text { Massey, MA, BM } \\
\text { BCh, DPhil }\end{array}$ & $\begin{array}{l}\text { Cardiff University, } \\
\text { UK }\end{array}$ & $\begin{array}{l}\text { Designed and } \\
\text { conceptualized study; wrote } \\
\text { first paper draft; reviewed } \\
\text { and critiqued manuscript }\end{array}$ \\
\hline
\end{tabular}

Appendix 2 Coinvestigators

Coinvestigators are listed at links.Iww.com/WNL/B358 


\section{References}

1. Huntington's Disease Collaborative Research Group. A novel gene containing a trinucleotide repeat that is expanded and unstable on Huntington's disease chromosomes: the Huntington's Disease Collaborative Research Group. Cell 1993;72:971-983.

2. Andrew SE, Paul Goldberg Y, Kremer B, et al. The relationship between trinucleotide (CAG) repeat length and clinical features of Huntington's disease. Nat Genet 1993;4: 398-403.

3. Duyao M, Ambrose C, Myers R, et al. Trinucleotide repeat length instability and age of onset in Huntington's disease. Nat Genet 1993;4:387-392.

4. Bates GP, Dorsey R, Gusella JF, et al. Huntington disease. Nat Rev Dis Prim 2015;1: 15005.

5. Craufurd D, Snowden J. Neuropsychiatry and neuropsychology. In: Bates GP, Tabrizi SJ, Jones L, editors. Huntington's Disease, 4th ed. Oxford University Press; 2014: $36-65$.

6. Scahill RI, Zeun P, Osborne-Crowley K, et al. Biological and clinical characteristics of gene carriers far from predicted onset in the Huntington's Disease Young Adult Study (HD-YAS): a cross-sectional analysis. Lancet Neurol 2020;19:502-512.

7. Paulsen JS, Long JD, Johnson HJ, et al. Clinical and biomarker changes in premanifest Huntington disease show trial feasibility: a decade of the PREDICT-HD study. Front Aging Neurosci 2014;6:78.

8. Tabrizi SJ, Scahill RI, Owen G, et al. Predictors of phenotypic progression and disease onset in premanifest and early-stage Huntington's disease in the TRACK-HD study: analysis of 36-month observational data. Lancet Neurol 2013;12:637-649.

9. Orth M, Handley OJ, Schwenke C, et al. Observing Huntington's disease: the European Huntington's Disease Network's REGISTRY. PLoS Curr 2010;2:RRN1184.

10. Eddy CM, Parkinson EG, Rickards HE. Changes in mental state and behaviour in Huntington's disease. Lancet Psychiatry 2016;3:1079-1086.

11. Unified Huntington's Disease Rating Scale: reliability and consistency. Mov Disord 1996; 11: 136-142.

12. Fisher R. On the "probable error" of a coefficient of correlation deduced from a small sample. Metron 1921;1:3-32.

13. GeM-HD Consortium. Identification of genetic factors that modify clinical onset of Huntington's disease. Cell 2015;162:516-526.

14. Genetic Modifiers of Huntington's Disease (GeM-HD) Consortium. CAG repeat not polyglutamine length determines timing of Huntington's disease onset. Cell 2019; 178:887-900.

15. Landwehrmeyer GB, Fitzer-Attas CJ, Giuliano JD, et al. Data analytics from ENROLL-HD, a global clinical research platform for Huntington's disease. Mov Disord Clin Pract 2017;4:212-224.

16. Dorsey ER. Characterization of a large group of individuals with Huntington disease and their relatives enrolled in the COHORT study. PLoS One 2012;7:e29522.

17. Lee JM, Ramos EM, Lee JH, et al. CAG repeat expansion in Huntington disease determines age at onset in a fully dominant fashion. Neurology 2012;78:690-695.

18. Rinaldi C, Salvatore E, Giordano I, et al. Predictors of survival in a Huntington's disease population from southern Italy. Can J Neurol Sci 2012;39:48-51.

19. Snell R, MacMillan J, Cheadle J, et al. Relationship between trinucleotide repeat expansion and phenotypic variation in Huntington's disease. Nat Genet 1993;4:393-397.

20. Illarioshkin SN, Igarashi S, Onodera O, et al. Trinucleotide repeat length and rate of progression of Huntington's disease. Ann Neurol 1994;36:630-635.

21. Kieburtz K, MacDonald M, Shih C, et al. Trinucleotide repeat length and progression of illness in Huntington's disease. J Med Genet 1994;31:872-874.

22. Langbehn DR, Brinkman RR, Falush D, Paulsen JS, Hayden MR. A new model for prediction of the age of onset and penetrance for Huntington's disease based on CAG length. Clin Genet 2004;65:267-277.

23. Wexler NS, Lorimer J, Porter J, et al. Venezuelan kindreds reveal that genetic and environmental factors modulate Huntington's disease age of onset. Proc Natl Acad Sci USA 2004;101:3498-3503.

24. Oosterloo M, Bijlsma EK, van Kuijk SM, et al. Clinical and genetic characteristics of late-onset Huntington's disease. Park Relat Disord 2019;61:101-105.

25. Fusilli C, Migliore S, Mazza T, et al. Biological and clinical manifestations of juvenile Huntington's disease: a retrospective analysis. Lancet Neurol 2018;17:986-993.
26. Cronin T, Rosser A, Massey T. Clinical presentation and features of juvenile-onset Huntington's disease: a systematic review. J Huntingtons Dis 2019;8:171-179.

27. Hensman Moss DJ, Pardiñas AF, Langbehn D, et al. Identification of genetic variants associated with Huntington's disease progression: a genome-wide association study. Lancet Neurol 2017;16:701-711.

28. Genetic Modifiers of Huntington's Disease (GeM-HD) Consortium. Identification of genetic factors that modify clinical onset of Huntington's disease. Cell 2015;162: 516-526.

29. Ellis N, Tee A, McAllister B, et al. Genetic risk underlying psychiatric and cognitive symptoms in Huntington's disease. Biol Psychiatry 2019;87:857-865.

30. Andrews SC, Langbehn DR, Craufurd D, et al. Apathy predicts rate of cognitive decline over 24 months in premanifest Huntington's disease. Psychol Med 2020:1-7.

31. Heinrichs RW, Zakzanis KK. Neurocognitive deficit in schizophrenia: a quantitative review of the evidence. Neuropsychology 1998;12:426-445.

32. Oosterloo M, Craufurd D, Nijsten H, van Duijn E. Obsessive-compulsive and perseverative behaviors in Huntington's disease. J Huntingtons Dis 2019;8:1-7.

33. Martinez-Horta S, Perez-Perez J, van Duijn E, et al. Neuropsychiatric symptoms are very common in premanifest and early stage Huntington's disease. Parkinsonism Relat Disord 2016;25:58-64.

34. Andrews SC, Craufurd D, Durr A, et al. Executive impairment is associated with unawareness of neuropsychiatric symptoms in premanifest and early Huntington's disease. Neuropsychology 2018;32:958-965.

35. Kessler RC, Berglund P, Demler O, Jin R, Merikangas KR, Walters EE. Lifetime prevalence and age-of-onset distributions of DSM-IV disorders in the National Comorbidity Survey Replication. Arch Gen Psychiatry 2005;62:593-602.

36. Cazeneuve C, Durr A. Genetic and molecular studies. In: Bates GP, Tabrizi SJ, Jones L, editors. Huntington's Disease, 4th ed. Oxford University Press; 2014: 109-130.

37. Zappacosta B, Monza D, Meoni C, et al. Psychiatric symptoms do not correlate with cognitive decline, motor symptoms, or CAG repeat length in Huntington's disease. Arch Neurol 1996;53:493-497.

38. Weigell-Weber M, Schmid W, Spiegel R. Psychiatric symptoms and CAG expansion in Huntington's disease. Am J Med Genet 1996;67:53-57.

39. Berrios GE, Wagle AC, Markova IS, et al. Psychiatric symptoms and CAG repeats in neurologically asymptomatic Huntington's disease gene carriers. Psychiatry Res 2001; 102:217-225.

40. Vassos E, Panas M, Kladi A, Vassilopoulos D. Effect of CAG repeat length on psychiatric disorders in Huntington's disease. J Psychiatr Res 2008;42:544-549.

41. Wright GEB, Collins JA, Kay C, et al. Length of uninterrupted CAG, independent of polyglutamine size, results in increased somatic instability, hastening onset of Huntington disease. Am J Hum Genet 2019;104:1116-1126.

42. Ciosi M, Maxwell A, Cumming SA, et al. A genetic association study of glutamineencoding DNA sequence structures, somatic CAG expansion, and DNA repair gene variants, with Huntington disease clinical outcomes. EBioMedicine 2019;48: $568-580$.

43. Escott-Price V, Bracher-Smith M, Menzies G, et al. Genetic liability to schizophrenia is negatively associated with educational attainment in UK Biobank. Mol Psychiatry 2019;25:703-705.

44. Orth M, Bronzova J, Tritsch C, Ray Dorsey E, Ferreira JJ, Gemperli A. Comparison of Huntington's disease in Europe and North America. Mov Disord Clin Pract 2017;4: 358-367.

45. Bachoud-Lévi AC, Ferreira J, Massart R, et al. International guidelines for the treatment of Huntington's disease. Front Neurol 2019;10:710.

46. Shahn Z, Li Y, Sun Z, Mohan A, Sampaio C, Hu J. G-computation and hierarchical models for estimating multiple causal effects from observational disease registries with irregular visits. AMIA Jt Summits Transl Sci Proc 2019;2019:789-798.

47. Sun Z, Li Y, Ghosh S, et al. A data-driven method for generating robust symptom onset indicators in Huntington's disease registry data. AMIA Annu Symp Proc 2017; 2017:1635-1644.

48. Long JD, Mills JA. Joint modeling of multivariate longitudinal data and survival data in several observational studies of Huntington's disease. BMC Med Res Methodol 2018; $18: 138$. 


\section{Neurology}

\section{Timing and Impact of Psychiatric, Cognitive, and Motor Abnormalities in Huntington Disease}

Branduff McAllister, James F. Gusella, G. Bernhard Landwehrmeyer, et al. Neurology 2021;96;e2395-e2406 Published Online before print March 25, 2021

DOI 10.1212/WNL.0000000000011893

\section{This information is current as of March 25, 2021}

\section{Updated Information \& Services}

References

Citations

Subspecialty Collections

Permissions \& Licensing

Reprints including high resolution figures, can be found at: http://n.neurology.org/content/96/19/e2395.full

This article cites 45 articles, 3 of which you can access for free at: http://n.neurology.org/content/96/19/e2395.full\#ref-list-1

This article has been cited by 4 HighWire-hosted articles: http://n.neurology.org/content/96/19/e2395.full\#\#otherarticles

This article, along with others on similar topics, appears in the following collection(s):

All Clinical Neurology

http://n.neurology.org/cgi/collection/all_clinical_neurology

All Neuropsychology/Behavior

http://n.neurology.org/cgi/collection/all_neuropsychology_behavior

Huntington's disease

http://n.neurology.org/cgi/collection/huntingtons_disease

Prevalence studies

http://n.neurology.org/cgi/collection/prevalence_studies

Information about reproducing this article in parts (figures,tables) or in its entirety can be found online at:

http://www.neurology.org/about/about_the_journal\#permissions

Information about ordering reprints can be found online:

http://n.neurology.org/subscribers/advertise

Neurology ${ }^{\circledR}$ is the official journal of the American Academy of Neurology. Published continuously since 1951, it is now a weekly with 48 issues per year. Copyright Copyright ( 2021 The Author(s). Published by Wolters Kluwer Health, Inc. on behalf of the American Academy of Neurology.. All rights reserved. Print ISSN: 0028-3878. Online ISSN: 1526-632X.

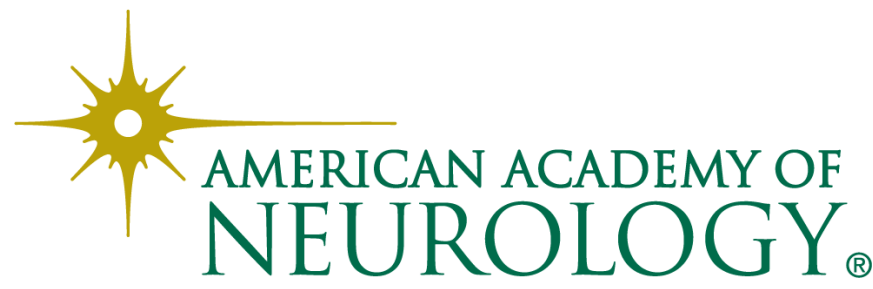

